This item was submitted to Loughborough's Research Repository by the author.

Items in Figshare are protected by copyright, with all rights reserved, unless otherwise indicated.

\title{
Feeling our way: academia, emotions and a politics of care
}

PLEASE CITE THE PUBLISHED VERSION

http://dx.doi.org/10.1080/14649365.2016.1240224

PUBLISHER

(c) Taylor and Francis

VERSION

AM (Accepted Manuscript)

\section{PUBLISHER STATEMENT}

This work is made available according to the conditions of the Creative Commons Attribution-NonCommercialNoDerivatives 4.0 International (CC BY-NC-ND 4.0) licence. Full details of this licence are available at: https://creativecommons.org/licenses/by-nc-nd/4.0/

\section{LICENCE}

CC BY-NC-ND 4.0

\section{REPOSITORY RECORD}

Askins, Kye, and Matej Blazek. 2019. "Feeling Our Way: Academia, Emotions and a Politics of Care". figshare. https://hdl.handle.net/2134/22461. 


\title{
Feeling our way: academia, emotions and a politics of care
}

Kye Askins (University of Glasgow) and Matej Blazek (Loughborough University)

Accepted in Social \& Cultural Geography, August 2016

\begin{abstract}
This paper aims to better understand the role of emotions in academia, and their part in producing, and challenging, an increasingly normalized neoliberal academy. It unfolds from two narratives that foreground emotions in and across academic spaces and practices, to critically explore how knowledges and positions are constructed and circulated. It then moves to consider these issues through the lens of care as a political stance towards being and becoming academics in neoliberal times. Our aim is to contribute to the burgeoning literature on emotional geographies, explicitly bringing this work into conversation with resurgent debates surrounding an ethic of care, as part of a politic of critiquing individualism and managerialism in (and beyond) the academy. We consider the ways in which neoliberal university structures circulate particular affects, prompting emotions such as desire and anxiety, and the internalisation of competition and audit as embodied scholars. Our narratives exemplify how attendant emotions and affect can reverberate and be further reproduced through university cultures, and diffuse across personal and professional lives. We argue that emotions in academia matter, mutually co-producing everyday social relations and practices at and across all levels. We are interested in their political implications, and how neoliberal norms can be shifted through practices of caring-with.
\end{abstract}

Key words: emotional geographies; care; ethics; justice; feminist praxis; neoliberalism

\section{Introduction}

This paper aims to better understand the role of emotions in academic practices, and their part in producing, and challenging, an increasingly normalized neoliberal academy (Berg, 2015), and the concomitant regulation of academic subjects (Davies \& Bansel, 2007). This follows Berlant's (2011) insistence on neoliberalism as a set of delocalised processes significant in changing 'norms of reciprocity', rather than a homogenising, global phenomenon whose forces have similar effects everywhere. Our argument revolves around two narratives, in which we individually reflect on emotions and social relations in spaces of 
research, and how these are folded through our wider personal geographies: as scholars with specific politics and motivations and as individuals situated in work and personal lives. The need to pay attention to emotions in academic work is an established argument (e.g. Bondi, 2013; Fitzpatrick \& Longley, 2014; Humble, 2012; Smith, Davidson, Cameron \& Bondi, 2009), albeit one that is still contested, ignored or subsumed as less than central or core to scholarly activities (Davidson, Bondi \& Smith, 2014). Here we focus specifically on the importance of emotions for establishing certain political orientations - evolving from the notion of care, and specifically the idea of caring-with - that carry the capacity to contest the "neoliberalization" (England \& Ward, 2007) of academia. Aware that "neoliberal practices always... exist in a more-than-neoliberal context" (Castree, 2006, p.3), we discuss emotions as operating within, beyond and against increasingly hegemonic processes that enclose and valorise "certain subjective/emotional dispositions" in academic environments (D'Aoust, 2014, p.267).

Our intention is to foreground emotions as connected to thought, as embodied experiences of which we keep trying to make sense. We wish to reiterate that emotions matter in the academy, from developing a topic or research approach, to later stages of knowledge circulation, and more broadly in being and becoming academics. Hence we move from this jointly voiced introduction to offer a brief framing of the key concepts on which we draw, without a more standard(ized) literature review ${ }^{1}$. We then foreground critical reflection, singling out two individual stories that highlight our particular experiences. This structure of the paper is intended to examine how the choices we make through, not despite, emotional experience are decidedly political, although frequently de-legitimised as such. This is precisely because these personal perspectives are also connected to the wider emotional dynamics of academia. We therefore shift authorial tone in the final two sections in the paper to scrutinise together how emotionality has a bearing for all scholars, not only those working on emotion, or those espousing feminist perspectives. Emotion, we argue, is central in and to everyday and structural conditions of our work.

Emphasising the lived stories also aligns the process of writing this paper with its key statement. Throughout the paper, we seek to challenge 'disembodied-objective' thought and this is reflected in our writing strategy. The paper stems from conversations, in person and via email, in which we were trying to make sense of current academic pressures and how they make us feel, conversations through which we thought and felt that a writing project may be mutually supportive in pushing back against these pressures. We started by narrating our emotions to each other, then sharing reflections to engage together in making sense of them, as both rational and emotional process, a more embodied-thinking. Unlike 
most papers we write, our initial audience was ourselves, and the second was each other, exploring emotions rather than sacrificing them on behalf of representation and rational articulation. We set no timescale for this, certain only that this should be a mutually supportive and nurturing project. It is our intention to maintain this architecture of writing in which the 'sense-making' of emotions does not displace those emotions from the conversation, and where we can still 'feel our way' while engaging with others. That is why we consider the two stories first in the paper, as we view them as having analytical primacy over a wider theorisation of literature.

We present these narratives as a "speech act" (Butler, 1997) that makes actions and choices possible as part of "being in the world". We decided to publish as a form of self-scrutiny, in which we hope that our embodied and emotional accounts can be part of transforming our comprehension of the world, and crucially feed back into our academic praxis (Braidotti, 2006). We follow Davids \& Willemse's (2014, p.2) account of the "fluidity and flexibility" of emergent positions of self and others, recognising how agency is invested in complex and diverse ways in social relationships. How we author academic texts is thus central to intersubjective knowledge production (Elizabeth \& Grant, 2013). We engage with literatures where relevant through our narratives and in the following discussion, in which we draw out key themes to raise questions for academia, ourselves, future research and thinkingfeeling/feeling-thought.

To frame such thinking-feeling, we briefly first set out resurgent social science interest in an "ethic of care", in particular aspects emphasising a politics of care (after Tronto, 1993; also Morgan, 2010). Care ethics is broadly conceptualised as one way in which social and economic life can be organised, and as a focus for policy and political activities which foregrounds moral significance in human relationships. Care ethics highlights interdependency as necessary to the embodied production of subjectivities and calls for recognition of relations and practices of care as an integral part of everyday ethics (Held, 2006). Amidst the range of conceptualisations and their embeddedness in cultural and geographical positions (Bowlby, McKie, Gregory, \& MacPherson, 2010), we understand care as meeting the needs, and maintaining the worlds, of ourselves and others (Sevenhuijsen, 1998). We see care, then, as highly relevant to contemplating our places in academia. Our move towards a politics of care is thus about more than maintaining; rather we seek to work towards fair and sustainable relations in academia as related to wider societies. Care, as Conradson (2011) argues, holds the potential "of facilitating new ways of being together" ( $p$. 454). 
There is a critique of care ethics as oppositional to an ethics of justice, where the former is framed as concerned with fostering interdependency, social bonds and reciprocal responsiveness to need across individual and wider social scales, and the latter as protecting equalities by consistently applying principles related to individual rights (see Clement, 1996; Held, 2004; Tronto, 2013. This paper points to theoretically nuanced debates regarding the tensions between ethics of care and justice, because, as academics, we are committed to social and spatial justice. In particular, we undertake participatory action research as a methodology that values transformative change as central in the co-production of knowledge, epistemologically orientated towards both care and justice (Askins, forthcoming). We thus refer to Held's (2006) call to reconcile these concepts by committing to justice in the sphere of "human rights (including social and economic ones as well as the political and civil)" (p.17), but recognising that "promoting care across continents may be a more promising way to achieve this than mere rational recognition" (ibid.). A critical interscaling here, across the individual and societal, and global, regional and local, prompts an understanding of ethics that incorporates issues of justice as a politics of care.

We are concerned with how we think and act as academics who care and are interdependent, wary of universalism or prescriptiveness in action and alert to the spatialities of social relations. Not all readers will share the pursuit of engagement beyond academia in their research in the same way as we do, yet the politics of care outlined in this paper go beyond an action research paradigm. Rather, they formulate a certain orientation to academic endeavour far more broadly, which necessarily involves giving and receiving care in reciprocal and complex ways, mindful of power inequalities caught up in such relations, and aware of relations within and outside academia. We argue that emotion is central to such care relations: emotion as producing and being produced through research situations, teaching and collegiate relations, in and across specific institutional structures and norms; as implicit in knowledge production, circulation and legitimisation.

We need, then, to be 'careful' about 'care'. Our interest is in care-giving activities in both their broadest sense and in their nuanced trajectories as they matter for being (and becoming) academics. We consider 'caring-for', the more hands on stage of care giving, but emphasise 'caring-about', the stage in which one nurtures caring ideas, intentions or feelings, reflecting on possible trajectories between the two within and beyond academia (Blazek et al., 2015). Following Raghuram (2014), we highlight the contestations over care as practice, and what this means for care as ethics. There is a risk that uncritical notions of care (as ethics and especially in policy) construct one-way dependent care, essentialise gendered roles of caring, and set up struggles for autonomy on behalf of both the carer and 
the cared. Such versions are rightly critiqued as reductionist, parochial, patriarchal and colonial (Bondi, 2008; Mahon \& Robinson, 2011), and we do not intend to reiterate them.

We need to be careful, too, about what we mean by emotion. Without entering detailed epistemological and ontological debates regarding emotions and affect (e.g. Bondi, 2014; Everts \& Wagner, 2012; Gregg \& Seigworth, 2011; Pile, 2010), we acknowledge emotions existing with regard to both their physical and cognitive aspects, individual/ised as well as socially circulating and spatially contextual (Smith et al., 2009). We consider affect as part of a wider coming-to-emotion process (Askins, 2016) and are specifically interested in how we (as academics) make sense of affect: how we, however paradoxical it seems (and feels), articulate what might be un-articulable, and in turn cope in and with the daily emotional realities of our situated positionalities. We conceive emotions as that part of the process where we consciously 'grapple' with our 'feelings', to reflexively consider their part in underpinning our work as political. Following Kobayashi, Preston \& Murnaghan (2011), we do not suggest that such a process is linear or comprehensive, yet it is important, along with the recognition of its imperfection. Depictions of our emotions in the following narratives do not presume that these terms should travel easily across cultures or languages. Indeed, even at a micro-scale of our own everyday contacts with the closest colleagues, we are aware of the disparity of reception that might be caused by translating emotional experience into words (cf. Anderson \& Smith, 2001).

\section{Kye's story}

This narrative hinges around experiences that have caused me to re-think who I am and what I do. The narrative is about long term relations with and within a voluntary sector organisation in the UK (hereafter AN-ORG). I approached AN-ORG, transparent from the start that I was interested in doing research with them, developing questions and methods together with "an ethical commitment to creating conditions for social change to be used by the community for their own purposes" (Cahill, 2007: 360). AN-ORG staff and I agreed at our first meeting that I should volunteer for a year or so, to build trust and better understand organisation and service user needs and issues 'from the inside', with a plan to morph into a research project after that. At the start, service delivery needs came first, and indeed my volunteering role continued for several years: as I developed relationships and become emotionally invested in AN-ORG's work, I felt that I should continue volunteering even as I started researching.

At around 18 months (time slipped as AN-ORG was faced with increasing client numbers and decreasing funding as a result of austerity measures in the UK), we explicitly discussed 
the research again in a staff meeting. I had chatted about it at various times in more ad hoc moments with various people, but at this point began to put together ideas and research questions with staff, based on their experiences and my growing engagements with service users and other volunteers. I was excited, because there were critical issues pertaining to geographies of social justice in such a project, my key area of research and teaching. Then I talked to academic colleagues with overlapping interests, who encouraged me, suggesting that I apply for UK Research Council funding to do this research. These are colleagues who I trust, with similar politics and values to me, and we particularly discussed the ethics of getting funding to ensure that the organisation and participants were rewarded financially for time and effort, and properly resourced with 'outputs'/outcomes of use to them (see Pain, 2004). I took these ideas to AN-ORG staff, and that sounded good to them.

The process moved on. I started writing a first draft of a proposal, outlining theoretical issues and (after some thought) using the uncomfortable euphemism of 'pilot study' to describe my involvement and engagement with the organisation so far. I did this to incorporate and justify participatory action research (PAR) approaches, explain how research questions had been developed together with AN-ORG, and the need to build trust in such research (WynneJones, North and Routledge, 2015). PAR is one way of doing community-engaged research, albeit one that I'm invested in due to my personal politics and experiences (see Askins, 2015, and later discussion). Actually, I had done some research in my volunteer role, in the form of an evaluation of service user and volunteer 'monitoring forms' which AN-ORG use to gather feedback as good practice. Such evaluation had been useful for AN-ORG and had also constituted some basis for discussion about research questions.

As I developed the conceptual framing, I thought about what might realistically stand a chance of being funded, and I went back to academic colleagues with greater experience in Research Council grant funding. Deciding that a feasible research project would need to involve more than one organisation in one place, it seemed serendipitous to work collaboratively on those issues and questions developed with AN-ORG. One of these colleagues had long term links with a similar voluntary sector organisation in another city, another had worked with PAR approaches for many years. These colleagues, and the organisation one had links with, agreed to be involved. I checked with AN-ORG director regarding widening the scope of research, and while not immediately in line with their thinking, we agreed to go forward with this broader remit. I re-worked the draft proposal accordingly, with help from colleagues (now co-investigators), who I must stress did not 'push' on this development but offered support and advice. I was still excited and feeling increasingly emotionally invested in, and caring about, the research. 
Then I took a full first draft of the proposal to AN-ORG ... and they had serious concerns with it. The main stumbling block, it turned out, was 'feminism'. I was shocked to discover that my (academic and politicised) understanding of feminism, as about equality for all in the broadest sense, about reciprocal care and respect - so central to AN-ORG's values and work - was not at all how feminism was read amongst staff, volunteers and service users. Volunteers especially interpreted feminism as being 'only for women' and exclusionary of men, a feminism that constructs caring roles as highly gendered, such that women care and men don't. They read the term feminism as an essentialised, identity politics version in which men are sidelined. This version clearly upset various people (of both genders) at AN-ORG, as men are valued and constructed as caring (and volunteering) 'just as much as women'. I felt dismayed on realising that there was such a disjuncture between this understanding and my own, and horrified that I had caused offence. I'd made assumptions, cocooned in a critical academic sphere in which nuanced and well-developed discourses of feminism are commonplace. ${ }^{1}$ Particularly problematic was that the language in the bid was too academic/obtuse, such that the feminism that I was outlining wasn't clear, in lay terms. The words 'feminist approach' were read and interpreted through a different frame than I intended. (I remain worried that the inclusive feminist project to which I adhere to has much work ahead to convey its message more lucidly, although that's not my focus here.)

There were other issues. The proposed project was bigger and more complex than anticipated, even given the extension to two organisations across two sites. The specifics of AN-ORG seemed 'a bit lost'. The time frame had stretched to incorporate Research Council expectations, and was now too long (two years) to be useful to them: UK voluntary sector organisations typically have to reapply for funding for core staff posts at least annually, and need supportive evidence that can keep up with ever-shifting policy and financial terrains. Further, while the bid had been careful to include outcomes that AN-ORG, service users and volunteers had suggested, there were outputs of no interest to them whatsoever, e.g. academic papers in 'high impact' peer-reviewed journals (?!), attendance at international academic conferences (?!). These aspects, as well as full university economic costings, had led to a final budget for the project that made me blush, when faced with it in AN-ORG offices. It wasn't stated, but we all knew that what AN-ORG could do with that amount of money would be far more directly beneficial to people involved. I felt ashamed.

I had two long and frank meetings with AN-ORG staff across a three week period to discuss how to move forwards. Meanwhile, I reflected on how l'd arrived at that point, leading myself and others along a specific road ... and why? At some time in the process, l'd had an annual 'appraisal' with my Head of Department, a largely performance-related discussion, setting 
out 'targets' to be achieved, now common in UK universities. My lack of 'serious' (read 'large') grant funding was cause for concern, as it had been every year, since I previously always applied for smaller, local pots of funding. During this period l'd also experienced an emotionally difficult time personally, after my father's death and family tensions arising from it, during which I was struggling to maintain a sense of self-worth. I realised that this emotional drain had bled into my academic role, also demeaning my sense of professional value, and the idea of a Research Council grant and some 'big papers' had become seductive. The more I reflected, the more upset I was with myself: I felt that I'd let everyone down at AN-ORG, as well as those colleagues who had also spent time and energy working up the bid proposal.

By the end of the second meeting with staff, it was clear that our intentions and respective understanding of the focus of AN-ORG's work were still compatible: reciprocal caring and challenging unequal power inequalities in society. I spent quite some time carefully trying to explain the mis-connect regarding feminism, and reiterated my commitment to working with everyone at AN-ORG, regardless of gender, ethnicity, age and other social-cultural categories. AN-ORG said they perhaps, maybe, possibly, might be able to sign up to the proposal ... [but]. There was a definite, loud though unspoken 'But'. (But they'd rather not ... But they still had reservations and needed more reassurances ... But it'd have to change a bit) ... And a long pause.

Then I said, what about if we revert to Plan A (meaning what we'd originally discussed over two years ago by now, in our very first meeting)? What about if I do shorter, unfunded, action research, around those research questions that we'd already agreed and that went into the funding proposal, but without all the academic whistles and bells and hoopla - and hoops to jump through? And they said 'yes' straight away. I felt relieved, yet also a loss of something inexplicable; in part some loss of their trust in me, in part loss of working with respected colleagues, and something else that I can't still describe. These feelings came with me into the research, and into analysis and write up of both a formal report for AN-ORG and an academic publication (re-negotiated with AN-ORG). These emotions have been part of knowledges produced, and will linger on into new academic pursuits.

\section{Matej's story}

I offer a personal narrative of approaching, negotiating and entering academia. It gives a different angle to Kye's story, but I also feel that this kind of story should be told. Not that it 
has not been expressed before - powerful accounts of the significance of emotions in the situatedness of academic identities do exist (Bondi, 1999; Domosh \& Bondi, 2014; Valentine, 1998) - but they tend to be written by 'established' academics, often retrospectively. In contrast, the 'emotional' voices of researchers in more precarious academic positions remain rare within academia, while ironically, they take on a somewhat more central role in more public outlets and media. ${ }^{2}$

I recall here an experience that might resemble those of many others. I wish neither to pity nor to celebrate (myself or others); yet it is impossible and perhaps counter-productive to dismiss memories of pride, shame, fear or joy. Rather, I want to highlight the recognition that a) coming to terms with becoming an academic can be a deeply emotional process, whether conceived as a success or failure (and that there is little to conceive outside this dichotomy); and that $b$ ) these emotions do and will affect what we do as researchers, educators, writers or at other levels of our social agency.

I began shaping my PhD plans in 2007, before the economic recession hit Europe and well before the austerity measures began transforming the UK higher education landscapes. I had the luxury to design and promote my own topic, driven and inspired by a personal history more than anything else, rather than look for pre-designed advertisements. I was lucky to find a good number of senior academics willing to listen, discuss, advise and endorse my ideas, several seeing me in person. After twelve months on the project, I then had the luxury to change its scope, adopting the role of a youth worker and looking ethnographically at children's practices in a single neighbourhood, rather than across various sites as was planned originally. An appendix to the thesis testified to the emotional drives behind these changes: the physical exhaustion from the sheer number of field activities in the initial project, the anxieties about failing to establish rapport with my participants at some research sites, the enjoyment of the organic nature of youth work and the excitement from the sense of relevance in exceeding my academic role. In letters to my supervisors, I mentioned feeling guilty for not enjoying the fieldwork in the sites where I struggled to get the research going, and for failing to plan the work more adequately. They rebuked this idea by suggesting that my academic work just might have turned out better at sites where I felt content and by prompting me to attend to my own emotions and 'more-than-research' activities of community youth work.

Undertaking the PhD was a powerful experience with emotions and care at the very foreground. Care was a resource not written or explicitly discussed in the project planning, but one that made it possible. I struggled from displacement, constantly moving between the 
UK and my home country, and also from a lack of regular income. Support and caring from my family, friends and department - from the former finding time to visit me, to the latter providing me with teaching and research assistance jobs to get by financially, while effectively distracting me from completing my $\mathrm{PhD}$ on time - was invaluable, both in practical terms and emotionally as I perceived their attentiveness (after Tronto 1989). Then, care also materialised in the complex geographies of the project and helped keeping it going. Care and caring were at the very centre of my young participants' agency (Blazek, 2015). As a youth worker, I had to defer my academic role and to rework who I was through learning, engaging and cooperating with other practitioners, but especially through caring about the young people and experiencing occasional powerful reciprocal manifestations of care from them. I appreciated that other academics cared about my project in more than intellectual ways; while, of course, my young research participants could not have cared less about the existence of academia. Those very emotional engagements with and in 'the field' and the attentiveness to emotions that embedded them prompted me to inquire into topics about which I had not really been interested before, including emotions and care.

I finished my PhD with a vision of becoming an academic who does more than academic work. Activities associated with the youth work role reinvigorated my interest in education and teaching, but I also felt excited by positioning myself between academia and community work, by doing academic research with relevance beyond academia, and community-based research with academic potential. It was a happy time: in retrospect, I am indebted to my PhD supervisors who allowed me to wander intellectually and practically; I felt encouragement from other academics who helped me to feel that my work was valuable; and the experience with both community youth work practitioners and young people made me feel perhaps capable as a youth worker.

By then, funding in the UK higher education sector had been reduced and streamlined, affecting the opportunities of finding academic jobs. I returned to my home country to wait for outcomes of several post-doctoral applications (some of which I failed barely and some badly) and immersed myself in community youth work. I became aware of the necessity to publish, but I had never really contemplated turning my thesis into a series of journal papers in the first instance, focusing on what I felt/thought mattered at the time: knowledge production (rather than dissemination) and the embodied dynamics of the research. I desired to continue in academia and I could not envision living in my home country, while at the same time I did not want to live too far away, to keep ties with someone for whom I deeply cared. 
Feeling exhausted from heavy periods of writing during PhD, I slowed down. The more I slowed down, the more applications were unsuccessful, and the more I was striving in nonacademic work (and the more I desired to return to academia), the further I felt I was getting from the academic world, contacts, networks, resources or debates. Soon I started a fascinating non-academic research project, working again at the researcher-practitioner interface and with a clear vision of relevance, but with no expectations and little time to write academically. Nine months after the PhD, I found myself with a backlog of materials but no energy, time or confidence to turn them into what could give me the job I wanted, caught in an indefinitely transitional period with no clear future or even a place to stay long-term. My ongoing research and its challenging topics fuelled me emotionally on a daily basis with anger, desolation, but also a lot of hope and compassion, just enough to focus on it, while I was failing terribly in personal life and relationships.

Then I received an offer that surprised me, a temporary lectureship in a UK geography department that matched my research profile. I was excited about re-entering a stimulating environment and taking up new pedagogic responsibilities. I met people who cared, even without knowing me before, who encouraged me, praised my work as important and in demand, and listened to my concerns and plans. It was a different expression of care from my PhD - instead of letting me wander off, I got straight and fair advice about making the job permanent: write 'world-leading'3 papers, get known beyond the narrow sub-disciplinary field and get funding even for the sake of funding (in that order), all in contrast to how I had worked before... After two years on a series of short-term contracts and despite (what I feel as) failing expectations on all three fronts, I was offered a permanent lectureship, my ultimate goal. Just at that time, I took the plunge and started adventures I had been postponing because of all the uncertainty: local volunteering, training in an area of helping professions, close personal relationships and even a local bottom-up participatory research project.

After my $\mathrm{PhD}$, I felt happy, despite all the uncertainty. Beginning writing this paper a few months after accepting the open-ended job offer, I am confused about experiencing one of the most difficult periods of time since I began engaging with academia. With the newly found security perhaps serving as a catharsis, making sense of why I felt how I felt led me to acknowledge that a range of emotions had been suppressed/repressed while I was focused on getting this job and they are resurfacing now: struggles to enjoy (or at least not to fear and hate) writing... diminished confidence from rejections of papers and proposals... frustrations from investing in projects that 'should' be done... anxieties about my workplace's culture of celebrating success publicly as a supposed means of support (raising the pressure 
about failing)... guilt of (sometimes) feeling disengaged from (some) colleagues, my institution and the whole sector... caring about someone living too far away... For the first time ever, I find myself struggling physically, from poor health and tiredness (despite not working more than before), and for the first time I acknowledge the possibility of changing my career (with no desire to do so).

This is the place when the making-sense of the emotional story needs to happen (written and revised months after I began writing the narrative). Looking back, I am concluding that my work, academic or not, has always been better, even in the view of my academic peers, when underpinned by an explicit attentiveness to emotions and by social relationships grounded in mutual care rather than attentiveness to success. I am lucky to be in a relatively established position, but now I think that my best chance to cement this security is paradoxically to attend to my own strengths that contradict much of the professional expectations and demands. I am slowly returning to where I feel my work is best: to write only the amounts and kinds of texts with which I can identify; to nurture and celebrate care as a researcher and a pedagogue in my everyday practice; to challenge the audit cultures and the prevalent notions of what counts in academia; to be caring and open to be caredabout by others; and to re-merge my work and personal life, not because I wish to burn out in either, but because they function best when underpinned by the same ethical and political standpoints.

\section{Making sense with care}

These are stories about the emotional aspects of who we are and what we do as academics, in order to co-produce knowledge and action in line with our ethical and epistemological orientations: how the emotional is inherent in envisioning a research activity, in developing relationships and trust, and in evolving processes that are often not envisaged. They are about negotiating relations across places and scales, resonating with debates around an ethics of care and careful praxis outlined briefly earlier. Specifically, unpacking them alerts us to how - and which - knowledges are being produced. At the core of the narratives are shifts in knowledge production processes entwined with emotional events and with the (felt) presence and absence of care. Kye's experience of appraisal as an audit process in which she was 'failing' was central to progressing potential research along lines that cared less for what had been advanced previously. Matej's experience of struggles to write and publish (enough) and precarious employment began to affect his care for others and himself, and also his capacities as researcher, eventually helping him see the two as intertwined. Our 
reflections prompted us to unpick the dominant values and relations of power involved in these shifts, and to mobilise such comprehension as a political stance towards being academics.

Both narratives revolve to some extent around balancing neoliberal academic pressures with our commitments to social and spatial justice. This struggle can be linked to increasing concern regarding the detrimental impacts of neoliberalized, free market universities, which normalise competition, implement widescale adoption of part-time, short-term, minimum wage contracts, and develop audit measures that adhere to narrow (minded) notions of academic "performance" to ever-escalating standards of "success" (Swan, 2010). Critique from both political economy and social justice paradigms points to the exclusionary, unjust nature of capitalism, and how it is economically misguided (Berg, 2013, 2015; Newson, 2012; Pain, Kesby \& Askins, 2011). More recently, these debates are being connected to issues of well-being (Gill, 2009; Moss, 2012), mental health (Parizeau et al., 2016), and calls for "slow scholarship" (Mountz et al., 2015). Our interest in the following sections is on explicitly drawing out the emotional effects of managerialism and individualism to think through a politics of care.

We are especially concerned about how neoliberal university structures circulate particular affective economies (Ahmed, 2004), which prompt emotions such as desire and anxiety, and the internalisation of competition and audit. Attendant emotions and affect can then reverberate and be further reproduced through university cultures and diffuse across personal and professional lives. It is important to acknowledge that academia remains a highly privileged site of work, and concerns here must be placed in wider circulations of power inequalities and exclusions. It is precisely in doing so, that we maintain emotions in academia matter, and we are interested in the political implications of this and in how we might shift neoliberal norms through an alternate vision of caring-with.

\section{Caring-with}

Writing about the need to move beyond economic and capital values, Skeggs (2014) believes that as social scientists we have "a duty" to search for the gaps beyond dominant discourse and structures, to discover "un-captured and better ways of being and doing" ( $p$. 19), and thereby paying attention to: 
our own and others' moments of love, care, and enchantment, to the connections that enable us to flourish [...to] block the logic of capital as it tries to capture absolutely everything. (Skeggs, 2014, p. 19)

This involves foregrounding social values, without ignoring economic ones, to constitute a political challenge to dominant processes of neoliberalism. Such a duty is in line with feminist care theory, which argues that "our everyday struggles around care denaturalize neoliberal claims of autonomous individuals" (Lawson, 2014, p. 2048). Lawson emphasises the paradox in the "absolute centrality" of care to our lives and societies, yet how capitalism devalues (notionally and economically) care and care work, securing care instead through exploitation. This yields a crisis that crosses class, ethnic, age, citizenship and other divides, a crisis that crucially, when conceived through a radical understanding of care, provides "both language and sites for a politics of alliance" (ibid.) These are arguments for making care visible, valuing care as essential to human ${ }^{4}$ relations and communities rather than 'rewarding' it individually. That is, "unhiding" (Katz 2001) care to disrupt the rationale of capital.

Making care visible involves paying attention to reciprocity. Reciprocal care is central to care ethics and, critically, does not signify equal relations or equality of position. Instead, these relations and positions (who is giving, who is receiving care) ebb and flow, being socially and spatially inflected. Care has significance for social relations within and across differing communities and groups (Conradson, 2011). We realise how Matej's experiences shift across a giving position in research, receiving encouragement as a PhD student, and being in less and more secure non-academic and academic employment. All of these positions affected personal and professional relations with a diverse range of people. Kye's experiences then interweave voluntary labour, giving and receiving support as volunteer, getting help and advice from academic colleagues, and being enabled to undertake research at AN-ORG, likewise combining an interplay of care giving and receiving across a spectrum of actors. Ultimately, we find ourselves positioned in networks of reciprocity, in which care is political precisely as a response to complex power inequalities (Bartos, 2012). This speaks to wider academic relations beyond research, and reciprocity as being a key point of connection between ethics of care and justice.

Thus, a politics of care considers individual relations (each one of us with any other) as also occurring at communal scales, through which care is given, offered, received or rejected, across wider social relations and networks. There are situations in which we care-about and-for and in which we are cared-about and-for (Held, 2006). These forms of care may 
overlap, but not necessarily: we may care for and about certain others, who may not care about or for us so much as about and for different people, who in turn care for and about other others. Such wider networks of care are always inter-scaled. In this vein, a politics of care can be conceived as an attempt to reconfigure the grounds for, and limits of, our agency as academic researchers. In such accounting, we can take inspiration from others who translate an ethics of care into an everyday politics; whether in the context of family spaces (Hoang, Yeoh \& Wattie, 2012) or transnational political ecology (Morgan, 2012).

Certainly, Mansbach (2012) argues that care can be a strategic political tool because it is deployed from a "context of marginalisation and devaluation" (p. 48), normatively constructed as limited to the sphere of the private, while "the opposite - public accomplishments, rationality, and autonomy - are the predominant values". Care thus becomes explicitly political in destabilising and challenging such binaries, in being made visible and central in public as much as private spaces and processes. Care matters in the academic context because of its marginalisation. It is, then, central to our critique of the neoliberal landscape and power dynamics of academia.

Such inter-scaled, complex networks of care resonate with Moss' (2012, p. 2) writing on being "stuck", "tired" and not feeling able to challenge unjust practices across neoliberal academia. She calls for an ontological politics (after Mol, 2010) which requires a "discursivematerial embodiment" as academics bring "specific, fleshed, affective bodies - and their limits - into workplace politics to construct a 'communiversity"' (see also mrs kinpainsby, 2008). Moss links this notion to an affirmative ethics concerned to generate relationships around social justice, and collective consciousness that may generate sustainable change. We identify such affirmative ethics with a politics of care that foregrounds reciprocity and interdependence in a communal - rather than modern individualist - project of caring-with: a conscious political stance enveloping practices of caring-for and - about collectively as a cornerstone of our academic identities, presents and futures. Conceiving such a politics of care demands that we recognise the mutability of caring practices across time and place, aware of our limitations yet accountable for our decisions. This requires that we remain attentive to culturally and spatially diverse constructions of care, need and reciprocal support (Jamieson, 2011), yet develop such reflexivity from reciprocal collaboration and social critique rather than individual introspection (Finlay, 2003). In the following section, we seek to envisage how attending to emotions can help facilitate this process. 
From our stories we contend that emotions are central to envisaging a politics of 'caringwith', and reflecting on our feelings is important in thinking and doing academic geographies. This claim might entail a number of propositions, such as moving us to consider psychodynamic theories and working through unconscious relations in processes of analysis (Bondi, 2014), or how psychosocial elements of the supervision process shape projects, analysis and writing (Lucey, 2011). But specifically, our narratives warn us that we should be wary of projection of the self onto others through caring relations, or employing altruism as a defence mechanism (Freud, 1993) against the anxieties of academia. This has two implications. First, aware that an ethic of care calls for an outward engagement with others as part of negotiating relations, we need to comprehend non-aligned gestures and reception of support and notions of care. For example, while Matej understood and appreciated the celebration of success at work as a gesture of solidarity and supportive intentions, it reproduced and re-internalised anxieties around failing to succeed, and affected his becoming as an academic. And although Kye envisaged a Research Council-funded project as being beneficial to AN-ORG financially, in costing for organisation, staff and participant time, this unintentionally emphasised economic over social values, projecting capitalist logic and performance pressures onto AN-ORG. As Kye worked through this misconnect, she felt aware of a fracturing of relations, and was reminded that relationships are not one-off, fixed entities once established:

They can wax and wane on both sides, and the processes by which they are developed and maintained often require forms of emotional interaction, expressed in embodied forms and practices as well as through words. (Kay \& Oldfield, 2011, p. 1277)

Indeed, for Matej a significant shift in PhD focus and way of working in the field, that redefined his project, was precisely through embodied forms and practices alongside dialogue to develop relations with research participants, academic colleagues, and other collaborators including community practitioners. Such involvement led to reciprocal outcomes that strengthened Matej's capacity as an academic.

The second implication is that caring-with as outward, open and dynamic practice can precipitate reciprocal engagement (in diverse ways) that may provide grounds for mitigating individual challenges and anxieties, and generate conditions in which the likelihood of beneficial collective outcomes will increase, even if their nature might not be predictable from the outset (Blazek et al., 2015). We outlined earlier how this writing evolved from conversations exploring how we felt, and, as time has slipped by, we have strengthened our 
understanding and our connection with an explicit agreement to work on this as a positive, nurturing project, as and when we have capacity to do so. Such a mutually supportive approach resonates with the "slow scholarship" advocated by Mountz et al. (2015). Meanwhile, problematizing whether writing this paper is the best we can do in producing and circulating this knowledge is also an important political act for us...

We are mindful that to write about emotions in our discipline remains less conventional, and involves opening our personal selves out to professional critique (Bondi 1999). We have to trust and hope that we will not be misread or that our emotional writing is unvalued (or held against us). The geographies of writing are different from face-to-face interpersonal relations, which are more immediately two-way and offer opportunity for dialogue and explanation. Yet writing with care, making sense of and constructing knowledge with emotion, is part of how our "specific, fleshed, affective bodies" (Moss, 2012, p. 2) relate to others. In the case of publishing academic work, these relations are through distanciated, iterative encounters, each adding to an emotional mapping and broader social relations in which we are situated. In writing this paper, we cannot escape how it fits into job appraisals, or how it will be received by the wider academic community or our close colleagues (who constitute an absent presence in the paper).

Clearly, we believe that engagement and dialogue are necessary to explore the role and impression of emotions in our scholarly praxis, yet the subjugation of emotions in dominant discourses of academia is a sensitive issue that must be approached care-fully. Robinson (1999) issues a word of caution against eradicating the conventions that inhibit emotions in academia, suggesting that voicing emotional insecurities might not necessarily be a way to heal them, at least not for everyone and on all occasions. She warns of new insecurities that might spring from failing to "draw a boundary between our personal pain and our academic enthusiasms" (p. 457). There is the potential that (private) emotions might cause damage to social relations in the workplace, that bringing emotions openly into academia may bring us to a situation "where our sense of who we are would be very insecure" (ibid.). We are sympathetic with these arguments, and are not suggesting that a politics of care should signal an emotional 'free-for-all' in research, writing or conference sessions, reinforcing existing power relations, or constituting new, equally unjust ones. However, we believe that insecurity is already a defining feature of contemporary academia, and working through and with - emotions, emphasising care and notions of communal, respectful, affirmative ethics, is a way to make inequalities visible and begin to address them. This call is about understanding critically what emotions are already doing, how they are working and being 
put to work in social relations, in our lives, and in our academic knowledge production and practices, and where care has the capability to intervene.

We do not seek to increase anxiety among those for whom emotionality in academia is anathema, rather we want to acknowledge the significance of emotionality in academia at all levels. We want to discuss emotions as they are relevant without apologies; and to extend the legitimisation of emotions in processes of inward academic reflexivity outward, as vital for transformative politics based on care that would challenge the affective and material expansions of neoliberalism. Despite the increasing "emotional turn" across the social sciences, emotions are still too often depoliticised and (re)presented as something inherent to feminist, social, critical scholars, as if emotions do not affect the academic identity of others (Thien, 2005). But there are many (rarely published, often verbalised) narratives, interweaving with ours, that suggest otherwise: stories of senior academics across various disciplines anxious to sustain their position and meet the challenge of "leadership", "success" and "excellence" (Tijdink, Verbeke \& Smulders, 2013); or of colleagues deeply worried that additional teaching workload will impair their research outputs, while simultaneously concerned about the lack of students to pay for their salaries (Geschwind \& Broström, 2015). Such narratives circle some informal academic spaces of discussion ${ }^{5}$, yet remain largely silent in peer review.

As contemporary debates regarding the politics of emotion and affect shift between the prepersonal propositions of non-representational theory (McCormack, 2005) and 'more-thanpersonal' structural perspectives of political economy (Mitchell \& Elwood, 2012), we want to re-acknowledge the importance of the personal-as-among-others, drawing on feminist and psychodynamic theories (Muñoz, 2009). There are connections across our narratives, to wider academic contexts, to literature regarding managerialist manipulation of emotions and affect as central to governance (Ahmed, 2012; Solomon, 2014), and emergent work on intimacy-geopolitics (Pain \& Staeheli, 2014). In the latter, intimacy is conceived as three coinciding "sets of relations": spatial relations that extend from proximate to distant; modes of interaction also expanding the personal to global and distant; and sets of practices connecting the body and (other bodies) far away - crucially without hierarchical ordering of one spatial scale over another. Such a framework helps us identify power relations and inequalities caught up in local, national and global processes, simultaneously acknowledging everyday intimacies and emotions as implicated through a range of inter-scaled relations that constitute academia. We read, then, emotions as central to caring-with, across intimate and political, personal and professional, private and public geographies, recognising such an outward orientation as a being with others that is concurrently inclusive of our inner selves. 


\section{Feeling our way ...}

Our key question is what can a politics of care do for us, and what can we do with it? We have no conclusions or prescriptive recommendations as to our (and wider academic) approaches and actions. Rather, we will (all) keep feeling our way, negotiating every context, situation and issue, with organisations, colleagues, participants and students. This is not new; feminist approaches in the social sciences and human geography have long advocated exactly this need to reflect, converse and negotiate, and we have drawn on just some of the critical work gone before. What is clear to us, given increasing drivers of individualism and competition, is that we need to keep reiterating and emphasising the personal as political, as embodied, limited and agentic academics, inherently involved with complex networks of reciprocity. There are and will be gaps in our narratives, and we do not call for removing so much as coming to terms with them, as a conscious stance to navigating how we are making sense of the knowledges we (are able to) produce, and the relationships that we develop, maintain and fracture.

We want to envisage a politics of care grounded in embodied, emotional and thoughtful perspectives, rendering emotions visible in process and relations. We want to hear and share more about the role of emotions in positive and inspiring examples that contest the dominant neoliberal framing of academia. Such examples seem rare at the moment (though see Participatory Geographies Research Group (2012) on strategies for self- and other-care in the academy, and Gibson, Rose \& Fitcher (2015) for creative ideas around "living in the Anthropocene"). However, our belief is that positive cases are hidden rather than rare, and one reason for publishing our writing project (as mentioned above) is to outline how working through the emotions of our experiences has ultimately been an affirmative and mutually supportive experience for us. That is, we envisage a politics of care that helps us view and practice an academia centred around values of generosity, collegiality and the communal, rather than grounded in a model of individualised/ising 'success' and 'achievement' in relation to benchmarked standards based on the logics of capital. Accountability remains vital, but a wider sense of accountability to others, including colleagues, funding bodies, taxpayers, students and local and global communities. This is collective accountability as reciprocal, and as more deeply felt (see Cope, 2008; Wright, 2008). This is care as both disposition and embodied practice (after Conradson, 2011).

Indeed, we have long been and are already generous and collegiate as a profession, offering much time, energy and free labour in the edifice of formal peer review, and in often 
informally supporting each other in reviewing work, organising events, covering teaching and multiple other activities that go beyond what may be expected individually to enable our scholarly community to work and, at times, flourish. The problem is that only economic and individual/ised aspects are valued formally, in promotion, institutional recognition and reward systems: what counts is who is named on grants and publications, and the myriad unequal power relations entrenched in systems and structures of competition. The social nature of offering and receiving support through reciprocal and interdependent relations remains valued only informally, and we suggest needs to be legitimatised regarding knowledge production, in research and more widely. Positive examples seem, to us, to be in short supply how working through the emotions of these experiences has been ultimately a positive experience for us

Foregrounding work explicitly as always within networks, as caring-with, can be part of "unhiding" (Katz, 2001) inequalities and shifting regimes of managerialism. This necessitates paying attention to emotion in all aspects of academic activities: from proposal stages of research, to reciprocal needs in empirical processes (beyond the potentially narrow 'impact' agenda in the UK, for example), and through to dissemination and writing research, cognizant of how leaving projects affects researchers and participants (Askins, 2009). We can begin to develop and embed site-specific strategies and frameworks within workplaces such that emotions can be discussed and enacted in respectful ways: not in terms of individualist navel gazing, or peer-reiterative 'woe is us', but critically raising the beyondrational in ethics committees and guidance, student supervision (Bondi, 2005), administrative roles, and the wide variety of meetings now set up in our online calendars, and in promotions and awards boards. We can continue to challenge the traditional Enlightenment withdrawal from desire in academic working, and especially risk advancing the personal, aware of an academic communality ready to care.

\section{Notes}

1. Of course, feminism/s are deeply contested in academia. What I am saying here is that the literatures and colleagues I engage with generally share a more poststructural version of feminism (for shorthand purposes here) as a starting point.

2. The Guardian series on mental health in higher education is a prime example from the UK context (https://www.theguardian.com/education/series/mental-health-a-university-crisis). 
3. 'World-leading' is a reference to the description of the top class of academic outputs, as considered by the Research Excellence Framework (REF), the national audit of research in the UK.

4. This can be extended to thinking about more-than-human relations, although beyond the scope of this paper.

5. See for example the blog postings on www.musicfordeckchairs.com .

\section{References}

Ahmed, S. (2004). The Cultural Politics of Emotions. London: Routledge.

Ahmed, S. (2012). On Being Included: Racism and Institutional Life. Durham NC: Duke University Press.

Anderson, K. \& Smith, S. (2001) Editorial: Emotional Geographies. Transactions of the Institute of British Geographers, 26(1), 7-10.

Askins, K. (forthcoming). Participatory Geographies. International Encyclopaedia of Geography: People, the Earth, Environment and Technology. London: Wiley-Blackwell.

Askins, K. (2016). Emotional citizenry: everyday geographies of befriending, belonging and intercultural encounter. Transactions of the Institute of British Geographers, DOI:

10.1111/tran.12135. Retrieved from http://onlinelibrary.wiley.com/doi/10.1111/tran.12135/full

Askins, K. (2015). Being together: everyday geographies and the quiet politics of belonging. ACME: International E-Journal for Critical Geographies, 14(2), 461-469.

Askins, K. (2009). 'That's just what I do': placing emotion in academic activism. Emotion, Space and Society, 2(1), 4-13.

Bartos, A. E. (2012). Children caring for their worlds: The politics of care and childhood. Political Geography, 31(3), 157-166.

Berg, L.D. (2013). Hegemonic geographies and their 'others': Towards an interlocking approach to emplacing geographical knowledges under academic capitalism. Dialogues in Human Geography, 3(2), 200-204.

Berg, L.D. (2015). Rethinking the PhD in the age of neoliberalization. Geojournal, 80(2), 219224.

Berlant, L. (2011). Cruel Optimism. London: Duke University Press.

Blazek, M. (2015) Rematerialising Children's Agency: Everyday Practices in Post-Socialist Estate. Bristol: Policy Press. 
Blazek, M., Smith, F.M., Lemešová, M., Hricová, P. (2015) Ethics of care across professional and everyday positionalities: (un)expected impacts of participatory video with young female carers in Slovakia, Geoforum, 61, 45-55.

Bondi, L. (1999). Stages on Journeys: Some Remarks about Human Geography and Psychotherapeutic Practice. The Professional Geographer, 51(1), 11-24.

Bondi, L. (2005) The place of emotions in research: from partitioning emotion and reason to the emotional dynamics of research relationships. In Davidson, J., Bondi, L. and Smith, M. (Eds) Emotional Geographies. Aldershot: Ashgate.

Bondi, L. (2008). On the relational dynamics of caring: a psychotherapeutic approach to emotional and power dimensions of women's care work. Gender, Place and Culture, 15(3), 227-243.

Bondi, L. (2013). Research and therapy: generating meaning and feeling gaps. Qualitative Inquiry, 19(1), 9-19.

Bondi, L. (2014). Feeling insecure: a personal account in a psychoanalytic voice. Social and Cultural Geography, 15(3), 332-50.

Bowlby, S., McKie, L., Gregory, S. \& MacPherson, I. (2010). Interdependency and Care over the Lifecourse. London: Routledge.

Butler, J. (1997). Excitable Speech: A Politics of the Performative. London: Routledge.

Cahill, C. (2007). Repositioning Ethical Commitments: Participatory Action Research as a Relational Praxis of Social Change. ACME: International e-Journal for Critical Geographies, 6(3), 360-373.

Castree, N. (2006) From neoliberalism to neoliberalisation: consolations, confusions and necessary illusions. Environment and Planning A, 38(1), 1-6.

Clement, G. (1996) Care, Autonomy, and Justice: Feminism and the Ethic of Care. Boulder: Westview Press.

Conradson, D. (2011). Care and Caring. In V.J. Del Casino, M.E. Thomas, P. Cloke \& R. Panelli (Eds.), A Companion to Social Geography. London: Blackwell.

Cope, M. (2008). Becoming a Scholar-Advocate: Participatory Research with Children. Antipode, 40, 428-435.

D'Aoust, A.-M. (2014) Ties that bind? Engaging emotions, governmentality and neoliberalism: Introduction to the Special Issue. Global Society, 28(3), 267-276.

Davies, B. \& Bansel, P. (2007) Neoliberalism and education. International Journal of Qualitative Studies in Education, 20(3), 247-259.

Davids, T. \& Willemse, K. (2014). Embodied engagements: Feminist ethnography at the crossing of knowledge production and representation. Women's Studies International Forum, 43, 1-4. 
Davidson, J., Bondi, L. \& Smith, M. (2014). An emotional contradiction. Emotions, Space and Society, 10, 1-3.

Domosh, M. \& Bondi, L. (2014) Remembering the making of Gender, Place and Culture. Gender, Place and Culture, 21(9), 1063-1070.

Elizabeth, V. \& Grant, B. M. (2013). 'The spirit of research has changed': reverberations from researcher identities in managerial times. Higher Education Research and Development, 31(1), 122-135.

England, K. \& Ward, K. (2007) Neoliberalization: States, Networks, Peoples. Oxford: Blackwell Publishers.

Everts, J. \& Wagner, L. (2012). Guest Editorial: Practising emotions. Emotion, Space and Society, 5(3), 174-176.

Finlay, L. (2003). The reflexive journey mapping multiple routes. In L. Finlay \& B. Gough, (Eds.), Reflexivity: A Practical Guide for Researchers in Health and Social Sciences. Oxford: Wiley \& Sons.

Fitzpatrick, K. \& Longley, A. (2014). Embodiment and affect in research collaborations. Emotions, Space and Society, 12, 49-54.

Freud, A. (1993). The Ego and the Mechanisms of Defence. London: Karnac Books.

Geschwind, L. \& Broström, A. (2015). Managing the teaching-research nexus: ideals and practice in research-oriented universities. Higher Education Research \& Development, 34(1), 60-73.

Gibson, K., Rose, D.B. \& Fincher, R. (Eds.) (2015). Manifesto for Living in the Anthropocene. NY: Punctum Books.

Gill, R. (2009). Breaking the silence: the hidden injuries of neoliberal academic. In R. Flood \& R. Gill (Eds.), Secrecy and Silence in the Research Process: Feminist Reflections. London: Routledge.

Gregg, M. \& Seigworth, G.J. (Eds.). (2011). The Affect Theory Reader. Durham, NC: Duke University Press.

Held, V. (2004) Care and justice in the global context. Ratio Juris: An International Journal of Jurisprudence and Philosophy of Law, 17(2), 141-155.

Held, V. (2006). The Ethics of Care: Personal, Political, and Global. Oxford: Oxford Uni. Press.

Hoang, L.A., Yeoh, B.S.A. \& Wattie, A.M. (2012). Transnational labour migration and the politics of care in the Southeast Asian family. Geoforum, 43(4), 733-740.

Humble, D. (2012). "This isn't getting easier": Valuing emotion in development research. Emotion, Space and Society, 5(2), 78-85. 
Jamieson, L. (2011). Intimacy as a Concept: Explaining Social Change in the Context of Globalisation or Another Form of Ethnocentrism? Sociological Research Online, 16(4), 15 www.socresonline.org.uk/16/4/15.html.

Jöns, H. (2016) Modern school and university. In Lightman, B. (Ed.) A Companion to the History of Science. Oxford: Blackwell.

Katz, C. (2001). Hiding the target: social reproduction in the privatized urban environment. In Minca, C. (Ed.), Postmodern Geography: Theory and Praxis. Oxford: Wiley.

Kay, R. \& Oldfield, J. (2011). Emotional Engagements with the Field: A View from Area Studies. Europe-Asia Studies, 63(7): 1275-1293.

Kobayashi, A., Preston, V. \& Murnaghan, A.M. (2011). Place, affect, and transnationalism through the voices of Hong Kong immigrants to Canada. Social and Cultural Geography, 12(8), 871-888.

Lawson, V. (2014). Symposium: The Kilburn Manifesto: after neoliberalism? Discussant comments. Environment and Planning A, 46(9), 2046-2049.

Lucey, H. (2011). Sibling ghosts in the machine: Sibling transference in PhD studentsupervisor relationships. Journal of Psycho-Social Studies, 5(2), 217-228.

Mahon, R. \& Robinson, F. (Eds.). (2011). Feminist Ethics and Social Policy: Towards a New Global Political Economy of Care. Vancouver: Uni. of British Columbia Press.

Mansbach, D. (2012). The Strategic Use of the Politics of Care: The Israeli Checkpoint Watch Movement. Feminist Theory, 13(1), 43-58.

McCormack, D. (2006). For the love of pipes and cables: a response to Deborah Thien. Area, 38(3), 330-332.

Mitchell, K. \& Elwood, S. (2012). Mapping children's politics: the promise of articulation and the limits of nonrepresentational theory. Environment and Planning D: Society \& Space, 30(5), 788-804.

Mol, A. (2010). Care and its values: Putting good food into nursing homes. In A. Mol, I. Moser, I. \& J. Pols (Eds.), Care in Practice: On Tinkering in Clinics, Homes, and Farms. Bielefeld: Transcript, 215-234.

Morgan, K. (2012). Local and green, global and fair: the ethical foodscape and the politics of care. Environment and Planning A, 42(8), 1852-1867.

Moss, P. (2012). Taking Stock in the Interim: The Stuck, the Tired, and the Exhausted. Antipode Foundation (Available at http://radicalantipode.files.wordpress.com/2012/10/mossresponse.pdf) Accessed 10 December 2014.

Mountz, A., Bonds, A., Mansfield, B., Loyd, J., Hyndman, J. Walton-Roberts, M., Basu, R., Whitson, R., Hawkins, R., Hamilton, T. \& Curran, W. (forthcoming). 'For Slow Scholarship: A Feminist Politics of Resistance through Collective Action in the Neoliberal University'. ACME Available at moblab@lists.riseup.net Accessed 19 April 2015. 
mrs. kinpaisby (2008). Taking stock of participatory geographies: envisioning the communiversity'. Transactions of the Institute of British Geographers, 33(3), 292-299.

Muñoz, J.E. (2009). From surface to depth, between psychoanalysis and affect. Women \& Performance: A Journal of Feminist Theory, 19(2), 123-129.

Newson, J. (2012). Academic Feminism's Entanglements with University Corporatization. Canadian Journal of Cultural Studies, 28 Available at http://pi.library.yorku.ca/ojs/index.php/topia/article/view/36199 Accessed 10th March 2015.

Pain, R. (2004). Social geography: participatory research. Progress in Human Geography, 28(1), 1-12.

Pain, R., Kesby, M. \& Askins, K. (2011). Geographies of impact: power, participation and potential, Area, 43(2), 183-188.

Parizeau, K., Shillington, L., Hawkins, R., Sultana, F., Mountz, A., Mullings, B. \& Peake, L. (2016). Breaking the silence: A feminist call to action. The Canadian Geographer, early online version available at http://onlinelibrary.wiley.com/doi/10.1111/cag.12265/abstract

Participatory Geographies Research Group (2012). Connectivity, creativity, hope and fuller subjectivities: appreciating responses to the communifesto for fuller geographie'. Available at http://radicalantipode.files.wordpress.com/2012/12/pygyrg-reply.pdf

Pile, S. (2010). Emotions and affect in recent human geography. Transactions of the Institute of British Geographers. 35(1), 5-20.

Raghuram, P. (2014). Care as a relational ethic? Contestations over care and postcolonial thinking. Presentation at RGS-IBG international conference, London 2014.

Robinson, J. (1999). Gaps, intellectual enthusiasms, personal insecurities: response to "Stages on Journeys". The Professional Geographer, 51(3), 452-458.

Sevenhuijsen, S. (1998). Citizenship and the Ethics of Care. New York: Routledge.

Skeggs, B. (2014). Values beyond value? Is anything beyond the logic of capital? British Journal of Sociology, 65(1), 1-20.

Smith, M., Davidson, J., Cameron, L. \& Bondi, L. (2009). Emotion, Place and Culture. Burlington, VT \& Farnham: Ashgate.

Swan, E. (2010). States of white ignorance, and audit masculinity in English higher education. Social Politics, 17(4), 477-506.

Thien, D. (2005). After or beyond feeling? A consideration of affect and emotion in geography. Area, 37(4), 450-454.

Tijdink, J.K., Verbeke, R. \& Smulders, Y.M. (2013). Publication pressure and scientific misconduct in medical scientists. Journal of Empirical Research on Human Research Ethics, 9(5), 64-71.

Tronto, J. (1993). Moral Boundaries: A Political Argument for an Ethic of Care. London: Routledge. 
Tronto, J. (2013). Caring Democracy: Markets, Equality, and Justice. New York: New York University Press.

Valentine, G. (1998). "Sticks and stones may break my bones": a personal geography of harassment. Antipode, 30(4), 305-332.

Wright, M. (2008). Craven Emotional Warriors. Antipode, 40, 376-382.

Wynne-Jones, S., North, P. \& Routledge, P. (2015) Practising participatory geographies: potentials, problems and politics. Area, 47(3), 218-221. 